\title{
Anne Duprat, Vraisemblances. Poétiques et théories de la fiction, du Cinquecento à Jean Chapelain (1500-1670)
}

\section{Monica Pavesio}

\section{OpenEdition}

\section{Journals}

\section{Edizione digitale}

URL: http://journals.openedition.org/studifrancesi/5596

DOI: 10.4000/studifrancesi.5596

ISSN: 2427-5856

\section{Editore}

Rosenberg \& Sellier

\section{Edizione cartacea}

Data di pubblicazione: 1 septembre 2011

Paginazione: 400

ISSN: 0039-2944

\section{Notizia bibliografica digitale}

Monica Pavesio, «Anne Duprat, Vraisemblances. Poétiques et théories de la fiction, du Cinquecento à Jean Chapelain (1500-1670)», Studi Francesi [Online], 164 (LV | II) | 2011, online dal 30 septembre 2011, consultato il 13 janvier 2021. URL: http://journals.openedition.org/studifrancesi/5596 ; DOI: https:// doi.org/10.4000/studifrancesi.5596

Questo documento è stato generato automaticamente il 13 janvier 2021.

\section{(c) $($ ) $(9)$}

Studi Francesi è distribuita con Licenza Creative Commons Attribuzione - Non commerciale - Non opere derivate 4.0 Internazionale. 


\title{
Anne Duprat, Vraisemblances. Poétiques et théories de la fiction, du Cinquecento à Jean Chapelain (1500-1670)
}

\author{
Monica Pavesio
}

\section{NOTIZIA}

ANNE DUPRAT, Vraisemblances. Poétiques et théories de la fiction, du Cinquecento à Jean Chapelain (1500-1670), Paris, Champion, 2009, 408 pp.

1 R. Bray è stato uno dei primi, fin dal 1927, a sottolineare l'importanza dei trattati italiani del Cinquecento nella teoria letteraria francese del XVII secolo, insistendo in particolare sull'apporto delle Poetiche di Giulio Cesare Scaligero e di Ludovico Castelvetro sulla formazione del classicismo francese. Dalle poetiche italiane del Rinascimento al Classicismo francese, la teoria della finzione è stata, in effetti, come dimostra l'autrice nel suo interessante volume, il luogo privilegiato del confronto fra discorso letterario e discorso della fede e della morale.

2 A. Duprat, dopo aver illustrato con l'aiuto del Dictionnaire universel di Furetière le diverse accezioni francesi secentesche della parola "fable", intraprende l'analisi delle correnti razionaliste italiane, partendo dalle poetiche erudite del Cinquecento italiano (I Parte: La fiction en poétique. Les lumières d'Italie 1480-1570), dove la finzione è descritta come una delle figure privilegiate della poesia. Vista come una risposta alla condanna platonica della poesia come illusione, la Poetica di Aristotele, appena riscoperta, fa nascere una serie di nuove concezioni della finzione come produttrice di sapere nei trattati degli umanisti italiani.

3 Successivamente, nella seconda parte del volume (Poétiques de la vraisemblance 1560-1660), l'autrice si sofferma sulla seconda metà del Cinquecento, allorché, a seguito 
del Concilio di Trento e delle restrizioni imposte riguardo all'utilizzo letterario e filosofico della favola e dei miti, nascono nuove poetiche aristoteliche in difesa della dignità del discorso poetico, ad opera di Speroni, Tasso, Castelvetro e Guarini.

4 Ecco quindi che quando in Francia iniziano le grandi querelles sulle "regole", sullo stile, sui generi misti, sul romanzo, che vedono contrapposti gli Anciens e i Modernes, la maggior parte delle formule utilizzate sono il risultato del lungo dibattito che si è svolto un secolo prima in Italia e che un gruppo di eruditi "italianisants" ha importato in Francia verso gli anni '20 del Seicento. E questo ultimo passaggio, che porta all'elaborazione del classicismo, uno dei sistemi poetici più coerenti e più stabili che ha avuto l'ambizione di regolamentare la produzione poetica di un'intera nazione, viene illustrato dall'autrice nell'ultimo paragrafo dedicato a Jean Chapelain, il cui ruolo è stato determinante nell'introduzione in Francia dei nuovi modelli di regolarità.

5 L'interessante volume di Anne Duprat, risultato della tesi di dottorato discussa dall'autrice nel 1998 sotto la direzione di G. Forestier e D. Soullier, presso l'Università Paris-Sorbonne, si conclude con un ricco apparato bibliografico ed un utile indice dei nomi. 